\title{
LIXO DOMÉSTICO: UM RELATO DE EXPERIÊNCIA SOBRE A IMPORTÂNCIA DA DESTINAÇÃO E REUTILIZAÇÃO DE RESÍDUOS EM UMA ESCOLA MUNICIPAL DE FLORIANO/PI
}

\section{DOMESTIC GARBAGE: A REPORT OF EXPERIENCE ON THE IMPORTANCE OF DESTINATION AND WASTE REUTILIZATION IN A MUNICIPAL SCHOOL OF FLORIANO / PI}

José da Guia da Conceição Ferreira ${ }^{1}$; Marciléia de Sousa Batista ${ }^{2}$; Maria do Carmo Martins Ramos ${ }^{3}$; Paloma de Jesus Cipriano ${ }^{4}$; Elkejer Ribeiro da Cruz ${ }^{5}$

\section{INTRODUÇÃO}

Os problemas ambientais causados pela ação humana provêm da utilização de forma inadequada do meio ambiente. A produção crescente de lixo e as facilidades criadas para atender demandas de uma sociedade, sobretudo consumistas, produzem um excessivo volume de resíduos sólidos desnecessariamente sem que sejam considerados os cuidados e a atenção necessária para a eliminação destes resíduos. O objetivo principal deste trabalho é relatar a experiência dos autores na execução do projeto de extensão "Lixo doméstico: destinação e reutilização", produto do componente curricular "Projeto Integrador III", do curso de Licenciatura em Ciências Biológicas do Instituto Federal de Educação, Ciência e Tecnologia do Piauí (IFPI) - campus Floriano, na escola municipal Antônio Nivaldo da cidade de FlorianoPI.

\section{RELATO DE EXPERIÊNCIA}

As ações necessárias para o alcance da sustentabilidade ambiental devem ser vistas como um conjunto único, uma vez que nenhuma ação, de forma isolada, é capaz de propiciar ganhos significativos no enfrentamento dos atuais desafios socioambientais, cada vez mais em evidência, tanto no cenário nacional como internacional (BUARQUE, 2002, p. 25).

A atitude de reciclar, além de diminuir a quantidade de lixo a ser tratada e eliminada, contribui significativamente para a redução da extração de matérias-primas necessárias à produção de novos bens de consumo. Afinal, adotar a educação ambiental, colocando os resíduos recicláveis nos locais devidos, não nos custa nada e ainda promove uma melhor qualidade de vida para toda a população. Ter uma vida mais saudável depende tanto de uma política pública de serviços ambientalmente adequados de limpeza urbana quanto da atitude da população (BARBOSA, 2008, p. 1).

De maneira simples, a reciclagem pode ser entendida como o processo de 
reaproveitamento pelo qual passam objetos usados, a fim de que novos produtos possam ser confeccionados a partir deles. Economicamente, a reciclagem é geradora de riquezas, uma vez que as empresas se valem desse processo para a redução de custos no processo produtivo, ao passo em que contribuem para a preservação do meio ambiente (TAVARES, 2010, p. 92).

Dentro do projeto, surgiu a proposta de construção de um jogo mobile, para sistemas Android, que abordasse a temática sustentabilidade ambiental. Com base nessa ideia, foi desenvolvido o jogo "EcoGame", que traz a dinâmica da coleta seletiva de maneira interativa e encontra-se disponível para download na loja de aplicativos Play Store. O desenvolvimento do aplicativo surgiu por meio de uma parceria entre acadêmicos do curso de Tecnologia em Análise e Desenvolvimento de Sistemas (TADS) em conjunto com os autores, acadêmicos de Licenciatura em Ciências Biológicas do IFPI - campus Floriano.

Imagem 1: Protótipo da Ferramenta. Fonte: Própria
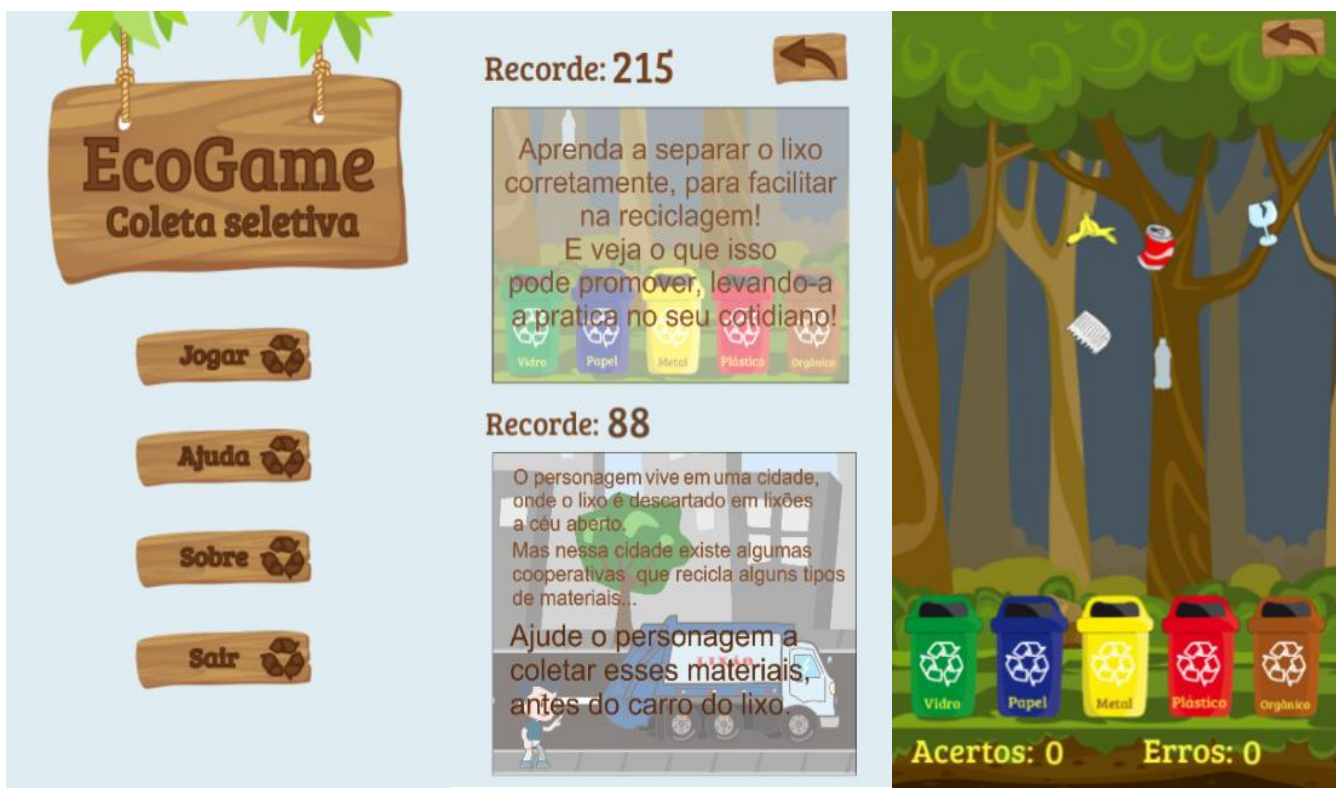

A etapa seguinte do projeto contou com uma visita prévia à Escola Municipal Antônio Nivaldo da cidade de Floriano-PI, para realizar uma avaliação diagnóstica do espaço escolar. Durante a visita, verificou-se a necessidade do aproveitamento de resíduos recicláveis e disseminação de informações a respeito desta temática para a comunidade escolar.

No dia da ação de extensão, foi realizada uma breve palestra: "Lixo doméstico: destinação e reutilização", sobre o aproveitamento e o descarte dos resíduos recicláveis. Em seguida, foi realizada uma oficina com atividades utilizando materiais tais como garrafas pet's, restos de canos de construções, barbantes, a serem reutilizados em atividades de recreação na escola, como brinquedos construídos a partir de materiais reciclados, atividades diárias em casa, como os afazeres domésticos, com objetivo de diminuir o acúmulo de lixo e consequentemente 
a poluição ambiental. Ao abordar sobre a coleta seletiva, foi apresentado o aplicativo "EcoGame" afim de mostrar um recurso tecnológico dinâmico e interativo sobre a temática, bem como a usabilidade do mesmo.

Imagem 1: Apresentação do projeto de extensão "Lixo doméstico: destinação e reutilização" na E. M. Antônio Nivaldo. Fonte: Própria

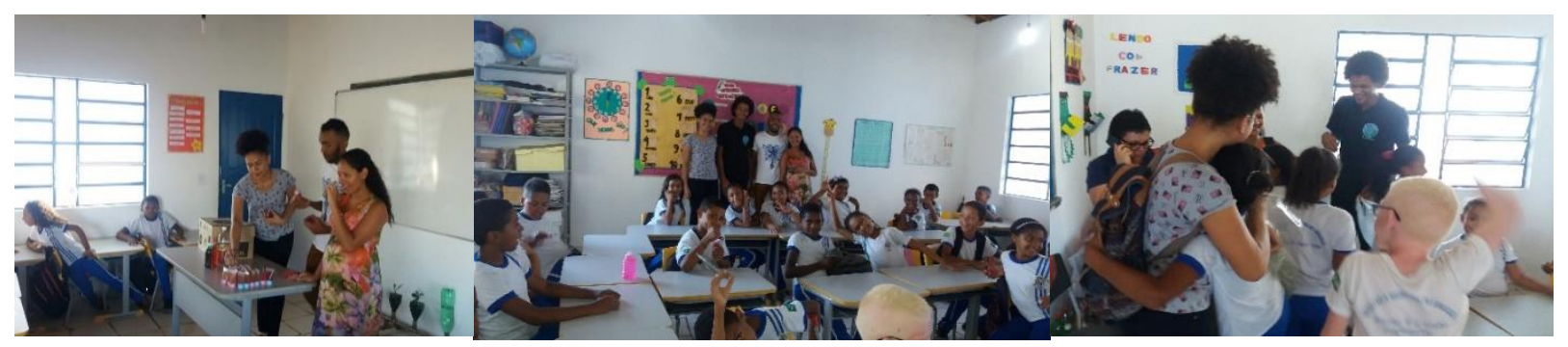

\section{CONSIDERAÇÕES}

Falar de resíduos sólidos é falar de vários desafios que necessitam ser superados, e se torna essencial a ajuda de pelo menos uma parcela significativa da sociedade. A consciência ecológica deve ser despertada ainda nos primeiros anos escolares das crianças e aperfeiçoada ao longo da vida por meio de ações sustentáveis. Entretanto, a Educação Ambiental não se caracteriza como uma disciplina do currículo escolar, e sim uma necessidade socioambiental que deve ser estimulada pela escola, pela comunidade e sobretudo no ambiente familiar.

A comunidade escolar em questão considerou gratificante a iniciativa dos acadêmicos. A maioria dos alunos demonstrou interesse e se propuseram a pôr em prática os conhecimentos adquiridos, como também disseminar esses saberes e sensibilizar os familiares e vizinhos quanto ao tratamento do lixo doméstico. Tal postura mostra o papel enriquecedor do projeto, já que é de suma importância o incentivo à mudança dos hábitos da população, fortalecendo o pensamento de que lixo é uma responsabilidade de todos.

Espera-se que com as informações sobre aproveitamento de resíduos recicláveis e a oficina as comunidades participantes tenham a iniciativa de mudança dos hábitos no que diz respeito ao aproveitamento de resíduos em situações cotidianas como, por exemplo: no momento da compra de determinados produtos industrializados, evitar os descartáveis.

\section{REFERÊNCIAS}

BUARQUE, C. Sérgio. Construindo o desenvolvimento local sustentável: metodologia de planejamento. Rio de janeiro: Garamond, 2002.

BARBOSA, Gisele Silva. O desafio do desenvolvimento sustentável. Revista Visões, 4.ed. v. 1, jan/jun, 2008. Disponível em: www.fsma.edu.br. Acesso em: 20 set. 2018. 
FERREIRA, et. al

LOUREIRO, C. F.; LAYRARGUES, P. P.; CASTRO, R. S. (Orgs.). Repensar a educação ambiental: um olhar crítico. São Paulo: Cortez, 2009.

TAVARES, M. C. Gestão estratégica. 3.ed. São Paulo: Atlas, 2010. 